\title{
3 Research Square

\section{Acquisition of Behavioral Skills After Manikin-Based Simulation of Neonatal Resuscitation by Fellows in Neonatology}

Maiana Darwich Mendes Guerreiro ( $\square$ maiana_mendes@msn.com )

Federal University of São Paulo

Joice Fabíola Meneguel Ogata

Federal University of São Paulo

Adriana Sanudo

Federal University of São Paulo

Ana Claudia Yoshikumi Prestes

Federal University of São Paulo

Maria Florencia Conzi

Federal University of São Paulo

Mandira Daripa Kawakami

Federal University of São Paulo

Milton Harumi Miyoshi

Federal University of São Paulo

Maria Fernanda Branco de Almeida

Federal University of São Paulo

Ruth Guinsburg

Federal University of São Paulo

\section{Research Article}

Keywords: Cardiopulmonary resuscitation, Newborn, Simulation training, Behavioral rating scale, anxiety, internship and residency, behavior.

Posted Date: October 18th, 2021

DOI: https://doi.org/10.21203/rs.3.rs-871915/v1

License: (c) (i) This work is licensed under a Creative Commons Attribution 4.0 International License.

Read Full License 


\section{Abstract \\ Background}

Behavioral performance of health professionals is essential for adequate patient care. There is little information on behavioral skills acquisition after simulation training of neonatal resuscitation. To assess the behavioral skills of fellows in neonatology before and after a simulation training program on neonatal resuscitation.

\section{Methods}

From March/2019 to February/2020, a prospective cohort with 12 second-year fellows in neonatology were evaluated during three training cycles ( 16 hours each) in manikin-based simulation of neonatal resuscitation with standardized scenarios. Each cycle lasted one month, followed by a 3-months interval. One video-recorded scenario of about 10 minutes was performed for each fellow at the beginning and at the end of each training cycle. Therefore, each fellow was recorded 6 times: before and after each one of three training cycles. Anxiety of the fellows was assessed by the Beck Anxiety Inventory applied before the first training cycle. The videos were independently analyzed in a random order by three trained facilitators using the Behavioral Assessment Tool. The behavioral performance was evaluated by repeated measures analysis of variance adjusted for anxiety and for previous experience in neonatal resuscitation.

\section{Results}

Fellows` overall behavioral performance improved comparing the moment before the first training and after the second training. The specific skills - communication with the team, delegation of tasks, allocation of attention, use of information, use of resources and professional posture - showed a significant improvement after the second month of training. No further gains were noted with the third training cycle. Anxiety was observed in $42 \%$ of the fellows and its presence worsened their behavioral performance.

\section{Conclusion}

An improvement in behavioral performance was observed comparing the moment before the first training and after the second training, without further gains after the third training. It is worth noting the important role of anxiety as a modulator of acquisition and retention of behavioral skills in health professionals in training.

\section{Background}


Under-five mortality is a public health issue. ${ }^{1}$ Worldwide, neonatal mortality represented $47 \%$ of deaths among children under five years old in $2019^{2}$ and intrapartum-related events contributed with around one third of these deaths. ${ }^{3}$ Neonatal resuscitation training could reduce $30 \%$ of neonatal deaths due to intrapartum-related events, especially in countries where peripartum care is insufficient. ${ }^{4}$

Neonatal resuscitation healthcare professionals require cognitive, technical, and behavioral skills to provide adequate assistance to the newborn at birth. ${ }^{5}$ In critical situations, behavioral performance may influence clinical outcomes. According to the Joint Commission, $72 \%$ of reported sentinel events in North American hospitals in 2004 were related to the lack of communication among the members of the teams that provided assistance to the mother and to the newborn infant. ${ }^{6}$ Again according to the Joint Commission, from 2004 to $2014,79 \%$ of the root causes for perinatal events were related to human factors. ${ }^{7}$

Teams working in the delivery room must be trained to carry out the necessary procedures and the coordinated action, with effective communication between its members, providing quality care and patient safety. ${ }^{8}$ The International Liaison Committee on Resuscitation (ILCOR) recommends that students and professionals who work in newborn assistance in the delivery room must be trained in their technical skills more than once a year, but there is insufficient evidence to determine the exact time between trainings for the better retention of knowledge by the students. ${ }^{9}$ Realistic simulation is a promising educational methodology to train technical and non-technical skills in Neonatology, as it is studentcentered and focused on previous experience-based learning. ${ }^{10,11}$ It allows participants' emotional involvement and it makes the experience as accurate as real life, providing training in leadership, communication, problem solving and teamwork in a safe and controlled environment. ${ }^{12}$

The acquisition of behavioral skills with simulation training in neonatology has not been extensively studied. These skills were analyzed by LeFlore et al., comparing self-directed learning with instructormodeled learning. The authors validated the Behavioral Assessment Tool to be used in the neonatal resuscitation scenarios and they found that, with the learning "modeled" by an instructor, the behavioral performance of the students was better. ${ }^{13,14}$ However, it is not known what the best ways are to design simulation training in order to improve both technical and behavioral skills of providers. In this context, this study aimed to assess behavioral skills of neonatology fellows in scenarios of resuscitation at birth before and after three training cycles with realistic simulation.

\section{Methods}

This was a single-center, prospective cohort study that included 12 second-year neonatal fellows from Escola Paulista de Medicina - Federal University of São Paulo, divided in four groups of three fellows each. This study was conducted from March 2019 to February 2020. The study was approved by the Ethics Committee on Research of Universidade Federal de São Paulo (approval number 3.128.093). 
Inclusion criteria were: neonatal fellows from the mentioned institution who agreed to participate through the consent form and image use form; they had to be certified by the Neonatal Resuscitation Program of Brazilian Society of Pediatrics that provides an 8-hour theoretical and practical training on initial steps, positive pressure ventilation with mask, tracheal intubation, chest compressions and use of medication. Also, they should be present in at least $70 \%$ of the curricular sessions of the institutional training of newborn care with realistic simulation provided by the fellowship program.

During the second year of neonatal fellowship, the fellows attend a manikin-based simulation training for three non-consecutive months. Each month of training is followed by three months of clinical activities, with a total of three months of simulation training during the year. Two weekly meetings are held: one in situ, at the obstetric ward, and one at the Laboratory of Realistic Neonatal Simulation. In each of the 120minute meetings, fellows participate in two to three scenarios of neonatal care in the delivery room. Over the course of the three months of training, fellows are subjected to approximately 60 different scenarios, focusing on technical skills (positive pressure ventilation, orotracheal intubation, chest compressions, and umbilical catheterization); preparation of materials/equipment in the delivery room; anamnesis and communication with the mother; communication with the obstetric team, and behavioral skills, with an emphasis on teamwork and leadership. All simulated clinical scenarios are videotaped. Clinical scenarios are elaborated by the facilitators, according to the objectives to be discussed. The scenarios carried out throughout the month are randomly distributed and may include more than one technical skill, but all fellows participate in the same scenarios until the end of the training. After each scenario, a debriefing is carried out to review the activities of the simulated scenario.

In this study, each training block had three fellows who participated together in the same standardized scenarios, each at a time being the leader of the resuscitation scenario. Although working together, each fellow was individually evaluated regarding the performance during the scenario that he/she had the leadership role. The other nine fellows of the Neonatal Fellowship Program were in clinical activities. On the first and last training days of each cycle, three scenarios, followed by a debriefing, were carried out, so that each fellow could be leader in one of these scenarios. Six videos were analyzed for each fellow: at the beginning and at the end of each of the three cycles of training (Figure 1). The signed consent guarantee that these videos will be discarded 10 years after the end of the study.

The videos were evaluated by three independent facilitators blinded to the training cycle and moment that the film was made. It was not possible to carry out the evaluation completely blindly, as the facilitators knew the students being evaluated. All the video analyses were performed after recording all six sessions from all fellows, after they have completed their Neonatal Fellowship Program. The evaluators were unaware of the sequence of training for each student. The randomization of the video sequence offered to each evaluator was done by the Random application (Developer: Mireia L. Ortola for loS system, 2019). The three evaluators were female, with a median age of 50 years (range: 42-50), that had been practicing neonatology for a median of 25 years (range: 10-25); all of them had taken the Realist Simulation Instructor Training Course promoted by Laerdal Medical (Brazil) and all of them were trained in behavioral assessment by the coordinator of the Simulation Laboratory. 
Behavioral performance was assessed in the videos using the "Behavioral Assessment Tool" (BAT). This tool had its internal consistence measured in several studies, with a Cronbach's alpha coefficient varying from 0,92 to $0,97,{ }^{14-18}$ but its validation is cited by Anderson et al $^{16}$ as unpublished. The BAT has ten variables related to behavioral skills and, to score of each one, the evaluator must choose from 0-4, ranging from poor to excellent or from inexperienced to expert. The analyzed behaviors were knowledge of the environment; anticipation and planning of possible problems; assumption of the leadership role; communication with other team members; workload distribution and delegation of responsibility; allocation of attention; use of all information; use of resources; recognition of limitations and request for help at the appropriate time; professional behavior and interpersonal skills, as well as the total score of the scale.

To adjust the results for possible confounders, the neonatal fellows were asked about the number of newly born infants that they participated in the delivery room care during the second fellowship year. Also, the Beck Anxiety Inventory (BAI) was applied to evaluate the anxiety before the beginning of the initial training. BAI is a validated tool to evaluate anxiety symptoms in a Likert scale from zero to four points. The final score classifies the anxiety as absent (0-10 points); mild (11-19); moderate (20-30); and severe (31-63). ${ }^{19,20}$ The written version of BAI was given to the fellows to be completed in the simulation setting or at home.

Fellows estimated their confidence during newborn care in the delivery room by a questionnaire adapted from Lee et al. ${ }^{21}$ The fellows answered the questionnaire in the first and last training day, estimating their self-confidence in four clinical situations: newborn infant with 35 weeks of gestational age (GA) born by vaginal delivery (situation 1); newborn infant with 33 weeks of GA born by cesarean section due to a hypertensive disorder of pregnancy (situation 2); neonate with 40 weeks of GA with meconium stained amniotic fluid (situation 3); and neonate with 26 weeks of GA born by cesarean section due to intrauterine growth restriction (situation 4). The answers were graduated by a Likert scale from zero to nine, as one being "uncomfortable" and nine "very comfortable".

A sample size calculation was made by estimating a 30\% improvement in the main outcome for the study, the global behavioral score assessed by BAT, with a standard deviation of BAT scores of 0.35 , based on a pilot study. An alpha error of $5 \%$ for a sample power of $80 \%$ was considered. According to these parameters, the participation of 12 fellows was needed.

The agreement between the facilitators for the BAT scale evaluated in the videos was analyzed using Cronbach's alpha. ${ }^{22}$ For the final score of each student in each video analyzed, the average of the scores obtained by the three evaluators in each of the items of the BAT and the total score were considered. The behavioral performance at the beginning and at the end of each of the three months of simulation training simulation, for each of the items of the BAT scale and for the total score, was compared by repeated measures analysis of variance (RM-ANOVA), and the differences were assessed by Bonferroni post-hoc test. ${ }^{23}$ The RM-ANOVA for each variable of the BAT and for its total score was adjusted for number of neonates assisted in the delivery room during the second year fellowship and for the score of 
the Beck Anxiety Inventory. Thus, the analysis by RM-ANOVA included the main effects "Training" (first, second or third month of training), "Moment" (beginning and end for each month of training) and the Interaction "Training" and "Moment", adjusted for "Anxiety" (BAI $\leq 10$ or $\geq 11$ ) and for the number of neonates received in the delivery room during the study year.

\section{Results}

Demographic data of the 12 second-year neonatal fellows are shown in Table 1. The fellows had an average age of 28.5 years, were mostly women, and had assisted around 100 neonates in the delivery room in each year of the Neonatal Fellowship Program. Before the beginning of the training cycle, the assessment of the presence of anxiety by the BAl showed that $41.7 \%$ of the fellows had some degree of anxiety (Table 1 ). 
Table 1

General characteristics of the neonatal fellows

\section{Data}

Age (years)*

Female**
$28.5 \pm 1.9(26-32)$

$11(91.7 \%)$

Medical graduation year**

2011

$1(8.3 \%)$

2014

$1(8.3 \%)$

2015

$10(83.4 \%)$

Number newborns assisted in the delivery room

During the first year of the Fellowship in Neonatology * $109 \pm 26(55-146)$

During the second year of Fellowship in Neonatology * $89 \pm 29(40-140)$

Previous training in the Neonatal Resuscitation Program**\# $12(100 \%)$

Previous training in Transport of High-Risk Neonates*\# $11(91,7 \%)$

Previous training in the Resuscitation of Preterm Infants**\#

$12(100 \%)$

Beck Anxiety Inventory***

$9(5-19,5)$

Score 0-10 - minimal level of anxiety**

$7(58,3 \%)$

Score 11-19 - mild level of anxiety**

$2(16,7 \%)$

Score 20-30 - moderate level of anxiety**

$3(25,0 \%)$

Score 31-63 - severe level of anxiety**

$0(0,0 \%)$

* Values expressed as mean \pm standard deviation (minimum - maximum); ** values expressed in

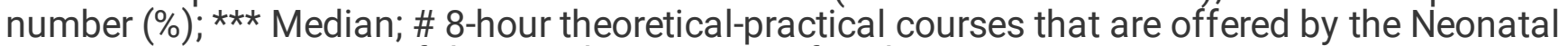
Resuscitation Program of the Brazilian Society of Pediatrics.

Regarding self-confidence in the four situations evaluated, there was an increase in the average confidence of the fellows from the initial moment of the simulation to the final moment. However, only in situations 2 and 4 , in which the degree of complexity was higher, the difference was significant (Table 2). 
Table 2

Residents' self-confidence for managing clinical situations related to the neonatal care soon after delivery.

\begin{tabular}{|c|c|c|c|}
\hline & $\begin{array}{l}\text { Before 1st } \\
\text { Training }\end{array}$ & $\begin{array}{l}\text { After Last } \\
\text { Training }\end{array}$ & $\begin{array}{l}\mathrm{p}- \\
\text { value }\end{array}$ \\
\hline Situation 1 & $7.67 \pm 1.15$ & $8.33 \pm 1.15$ & 0.136 \\
\hline Newborn with GA of 35 weeks born by vaginal delivery & $(6-9)$ & $(5-9)$ & \\
\hline Situation 2 & $5.83 \pm 1.34$ & $7.42 \pm 1.51$ & 0.005 \\
\hline $\begin{array}{l}\text { Newborn with GA of } 33 \text { weeks born by C-section due to pre- } \\
\text { eclampsia }\end{array}$ & $(4-8)$ & $(4-9)$ & \\
\hline Situation 3 & $6.42 \pm 2.11$ & $7.75 \pm 1.22$ & 0.063 \\
\hline $\begin{array}{l}\text { Newborn with GA of } 40 \text { weeks with meconium-stained } \\
\text { amniotic fluid }\end{array}$ & $(2-9)$ & $(5-9)$ & \\
\hline Situation 4 & $3.67 \pm 2.06$ & $5.92 \pm 2.27$ & 0.002 \\
\hline $\begin{array}{l}\text { Newborn with 26-week of GA born by C-section due to } \\
\text { intrauterine growth restriction. }\end{array}$ & $(1-7)$ & $(1-9)$ & \\
\hline
\end{tabular}

As for the agreement among the three evaluators of the BAT score, the Cronbach's alpha for each behavioral item ranged from 0.635 (domain - resource utilization) to 0.801 (domain - leadership assumption), and it was 0.769 for the total score, showing a good agreement. ${ }^{24}$

The mean score measured by the three independent evaluators for each item of the BAT scale individually and for the whole score, at the six time points, are shown in Figure $2 \mathrm{a}$ and 2b, respectively. There was an increase in the scores of all skills after the first training, with a decrease after the threemonth interval until the beginning of the second training. There was again an increase in the behavioral performance score for each of the individual domains after the second training. After this training, there was a decrease in performance until the beginning of the third training, without further improvements.

Table 3 shows the results of the BAT with the main effects "training" " (1st, 2nd or 3rd cycle of training) and "moment" (before and after each training) and the interaction between training and moment adjusted by "presence of anxiety" (BAI >10) and "number of newborns received by the fellows in the year of the study". The main effect "moment" was significant for the following BAT domains: communication with the team, delegation of tasks, allocation of attention, use of information, use of resources, professional attitude, and overall score of behavioral performance. The presence of anxiety modified the performance in the following domains: knowledge of the environment, allocation of attention, use of resources, asking for help in appropriate time and professional behavior, as well as in the total score of the scale. The posthoc analyses of the differences with the Bonferroni test are shown in Table 4. 
Table 3

Main effects, interactions and covariates evaluated by ANOVA for repeated measures for each domain and for the total BAT scale to assess the behavioral performance of neonatal fellows during training in realistic simulation of neonatal resuscitation

\begin{tabular}{|c|c|c|c|c|c|}
\hline BAT & Training & Moment & $\begin{array}{l}\text { Training* } \\
\text { Moment }\end{array}$ & Anxiety & $\begin{array}{l}\text { Neonates } \\
\text { received }\end{array}$ \\
\hline Knowledge of the environment & 0,199 & 0,075 & 0,149 & 0,013 & 0,759 \\
\hline $\begin{array}{l}\text { Anticipation of and planning for potential } \\
\text { problems }\end{array}$ & 0,742 & 0,214 & 0,146 & 0,207 & 0,872 \\
\hline Assumption of leadership role & 0,794 & 0,272 & 0,279 & 0,279 & 0,764 \\
\hline $\begin{array}{l}\text { Communication with other team } \\
\text { members }\end{array}$ & 0,466 & 0,010 & 0,242 & 0,177 & 0,392 \\
\hline Distribution of workload & 0,916 & 0,013 & 0,439 & 0,236 & 0,890 \\
\hline Attention allocation & 0,170 & $<0,001$ & 0,201 & 0,032 & 0,341 \\
\hline Utilization of all information & 0,207 & 0,004 & 0,462 & 0,098 & 0,733 \\
\hline Utilization of resources & 0,771 & 0,041 & 0,195 & 0,013 & 0,511 \\
\hline $\begin{array}{l}\text { Recognizes limitations/ Call for help early } \\
\text { enough }\end{array}$ & 0,391 & $>0,999$ & $<0,001$ & $<0,001$ & 0,658 \\
\hline $\begin{array}{l}\text { Professional behavior/ Interpersonal } \\
\text { skills }\end{array}$ & 0,190 & 0,025 & 0,201 & 0,014 & 0,598 \\
\hline Total & 0,400 & 0,009 & 0,048 & 0,031 & 0,863 \\
\hline
\end{tabular}


Table 4

Differences observed for the main effect "Moment" according to the post-hoc test of Bonferroni for each domain of BAT and for the whole scale.

\begin{tabular}{|c|c|c|c|}
\hline & 1st Training & 2nd Training & 3rd Training \\
\hline \multicolumn{4}{|c|}{ Communication with other team members } \\
\hline Before training & $1.64 \pm 0.66$ & $1.69 \pm 0.44$ & $1.75 \pm 0.47$ \\
\hline After training & $2.00 \pm 0.45$ & $2.17 \pm 0.56$ & $1.78 \pm 0.67$ \\
\hline $\mathrm{p}$-value & 0.063 & 0.015 & 0.886 \\
\hline \multicolumn{4}{|c|}{ Distribution of workload } \\
\hline Before training & $1.67 \pm 0.47$ & $1.78 \pm 0.43$ & $1.86 \pm 0.66$ \\
\hline After training & $2.08 \pm 0.38$ & $2.08 \pm 0.53$ & $1.94 \pm 0.72$ \\
\hline$p$-value & 0.026 & 0.103 & 0.656 \\
\hline \multicolumn{4}{|c|}{ Attention allocation } \\
\hline Before training & $1.75 \pm 0.38$ & $2.00 \pm 0.43$ & $2.03 \pm 0.36$ \\
\hline After training & $2.19 \pm 0.30$ & $2.33 \pm 0.38$ & $2.11 \pm 0.38$ \\
\hline p-value & 0.002 & 0.022 & 0.566 \\
\hline \multicolumn{4}{|c|}{ Utilization of all information } \\
\hline Before training & $1.78 \pm 0.46$ & $1.94 \pm 0.65$ & $1.92 \pm 0.51$ \\
\hline After training & $2.14 \pm 0.44$ & $2.42 \pm 0.45$ & $2.06 \pm 0.49$ \\
\hline $\mathrm{p}$-value & 0.061 & 0.014 & 0.472 \\
\hline \multicolumn{4}{|c|}{ Utilization of all resources } \\
\hline Before training & $2.03 \pm 0.36$ & $1.92 \pm 0.55$ & $2.08 \pm 0.35$ \\
\hline After training & $2.08 \pm 0.38$ & $2.33 \pm 0.32$ & $2.17 \pm 0.56$ \\
\hline$p$-value & 0.724 & 0.008 & 0.596 \\
\hline \multicolumn{4}{|c|}{ Professional behavior/ Interpersonal skills } \\
\hline Before training & $1.86 \pm 0.41$ & $1.97 \pm 0.61$ & $2.11 \pm 0.30$ \\
\hline After training & $2.08 \pm 0.47$ & $2.39 \pm 0.34$ & $2.11 \pm 0.41$ \\
\hline $\mathrm{p}$-value & 0.171 & 0.010 & $>0.999$ \\
\hline \multicolumn{4}{|l|}{ Total Score } \\
\hline Before training & $17.3 \pm 3.9$ & $18.1 \pm 4.1$ & $19.5 \pm 3.8$ \\
\hline
\end{tabular}




\begin{tabular}{|llll|}
\hline & 1st Training & 2nd Training & 3rd Training \\
\hline After training & $20.2 \pm 3.3$ & $21.9 \pm 2.7$ & $18.9 \pm 4.8$ \\
\hline p-value & $\mathbf{0 . 0 3 0}$ & $\mathbf{0 . 0 0 5}$ & 0.635 \\
\hline
\end{tabular}

\section{Discussion}

In this prospective cohort study of second-year neonatal fellows, a 4.5-points significant improvement in the BAT total score was observed between the initial time prior to any training and the moment after the second training, with no additional gains at the end of the third training. The presence of mild or moderate anxiety was an independent variable, decreasing the behavioral performance of the studied trainees. The self-confidence of neonatal fellows in assisting newborn infants in the delivery room increased after the three training cycles, especially in more complex clinical situations.

Some hypotheses have been raised for the lack of consistent improvement of the behavioral performance of neonatal fellows at the end of the last training. The trainees were not inexperienced in Realistic Simulation before the training because they had already participated in the Neonatal Resuscitation Program of the Brazilian Society of Pediatric. Another issue to be considered is the fact that the third training cycle took place in the last months of fellowship, when most trainees already have a certain degree of fatigue, anxiety, and loss of focus. Also, highlighting problems in the teaching model offered by this simulation program, the repetition of scenarios on the same topic, with only minor changes, may have contributed to the lack of interest in the training. Therefore, a change in our teaching program has been elaborated after the results of this study, offering more diverse and challenging scenarios during the last months of training.

For young adults' learning, novelty and challenge are important drivers. ${ }^{25}$ One of adult learning phases is the perception of a gap in their knowledge, and for this to happen, there needs to be a challenge, which can be internal or external, stimulated or not by the facilitator. ${ }^{24}$ This process may have been minimized by the previous experience with the Neonatal Resuscitation Program and by the repetition of scenarios. It is also worth mentioning the fact that the group of fellows were always the same, and it was possible to observe that some fellows, by the end of the year, were used to work together and were no longer concerned about establishing a communication in a closed loop.

Although the final result of the training was not as expected, it is interesting to observe the curve of acquisition, retention and loss of behavioral skills exhibited by the fellows in this study (Figure 2). There was a downward trend in behavioral performance between the end of each training cycle and the beginning of the next, showing that behavioral skill retention remains only for a few months. Patel et al. evaluated cognitive and technical skills in North American Pediatric residents. The authors showed that retention of technical skills starts to drop after 2-3 months of training. ${ }^{26}$ Matterson and colleagues showed a reduction in retention of technical skills after 4 months of Realistic Simulation training in 
neonatal resuscitation. ${ }^{27}$ Our data reinforce the need for periodic retraining in neonatal resuscitation for healthcare teams responsible for neonatal resuscitation to maintain previously acquired skills.

Regarding the specific behavioral skills, there was significant improvement between the beginning of the training and the end of the second training in the following skills: communication with the team, delegation of tasks, allocation of attention, use of information, use of resources, professional attitude, and the overall score of behavioral performance. Of the four behavioral domains that did not change with training (knowing the work environment, anticipating problems, taking the lead, and asking for help at an appropriate time), the first two may have been influenced by the lack of a longer filming time before the actual scenario. Also, not all scenarios allowed the evaluation of the behavior "request for help". Therefore, in some videos, the evaluators noted this behavior as "not evaluated", reducing the number of videos analyzed and decreasing the sample power. However, the absence of improvement in the leadership performance deserves special attention. The fact that the group of trainees was always the same may have influenced the teamwork, with the observation in some videos of a "shared" leadership, with two trainees providing commands. It was also noted that some fellows started the scenario as leaders, but lost the leadership, and another fellow assumed this role. The same finding was shown by Sawyer et al, in 2014. In their study, Pediatrics and Family Medicine residents received three simulation trainings on neonatal resuscitation and 15 teams of two residents completed all three training over a period of 9 months. A total of 45 resuscitation videos, 15 from each of the three simulation sessions, were reviewed and scored by two blinded reviewers using the BAT. Although BAT global score improved from the first to third session, assumption of leadership did not change throughout the simulation trainings. ${ }^{17}$

In the present study, approximately $42 \%$ of fellows had some degree of anxiety, according to the Beck Anxiety Inventory, and its presence significantly modified the trainees' performance in the following domains of the BAT: knowledge of the environment, allocation of attention, use of resources, request for help in appropriate time and professional behavior, as well as in the total BAT score. Al-Ghareeb et al. studied 33 nursing students to assess the influence of anxiety on their performance in a Realistic Simulation scenario and students with higher levels of anxiety showed worse technical, cognitive, and behavioral performance. ${ }^{28}$ The data obtained here and by Al-Ghareeb et al. suggest that attention to the mental health of professionals in training is critical for a full benefit of programs aimed at the acquisition of technical and behavioral skills in areas in which the need for decisions and actions at a rapid and consistent pace is decisive in the prognosis of patients.

In our study, there was an increase in the average confidence of the fellows when comparing the moment before any training in simulation with the moment after all training cycles for all clinical situations evaluated. However, only in situations of higher medical complexity, the difference was significant. This result cannot be attributed only to the experience provided by the realistic simulation training, but it occurred in the context of completing the whole Neonatal Fellowship Program developed in the university hospital. The role of exposure to realistic simulation in the confidence of health professional is controversial. A systematic review with 24 studies, published in 2012, suggested that there is no robust 
evidence to confirm that high-fidelity realistic simulation improves students' self-confidence ${ }^{29}$ However, in another systematic review published in 2019, the self-confidence of nursing students after Realistic Simulation training was evaluated in 29 studies and the results indicated that this teaching technique improved students' self-confidence. ${ }^{30}$

Overall, this study contributes to building knowledge about the acquisition and retention of behavioral skills of health professionals after realistic simulation training. The cohort design over one year, with three cycles of one month of training, followed by three months of "rest" (Figure 1), allowed us to verify the acquisition and retention of behavioral skills over time and not only the short-term effect of a single training session. It is worth noting the important role of anxiety as a modulator of acquisition and retention of behavioral skills in health professionals in training.

\section{Limitations}

Despite these findings, it is necessary to point out some limitations of the study. The sample of fellows was small, from a single center and chosen by convenience, nevertheless with a sample calculation showing sufficient power and with a prospective design that followed the fellows' performance throughout the year. It is important to consider that the video evaluators were present in some scenarios during data collection and knew the fellows. To minimize the bias of the unblinded evaluation, the randomization of the order of the videos analyzed by each evaluator decreased the subjectivity of the evaluation of each fellow individually. Another important limitation was the lack of a systematic assessment, in this study, about suggestions of facilitators and learners on how to optimize the training and avoid the lack of improvement in the third cycle of training. Maybe, by confronting both views, with a qualitative analysis, we could have identified opportunities to improve this learning experience.

\section{Conclusion}

In conclusion, an improvement in the behavioral skills of neonatal fellows in delivery room newborn care scenarios was observed between the time before any training and after the second training cycle, with no benefit after the final training cycle. Reported self-confidence in handling complex cases increased between the beginning and the end of the realistic simulation training, and anxiety presence was a modulator of trainees' behavioral performance.

\section{Abbreviations}

BAT (Behavioral Assessment Tool), BAI (Beck Anxiety Inventory), GA (gestational age), RM-ANOVA (repeated measures analysis of variance).

\section{Declarations}

Ethics Approval and consent to participate: The research protocol was approved by the Ethics Committee of Federal University of São Paulo (Unifesp - Escola Paulista de Medicina). Approval 
number: 3.128.093. All methods were performed in accordance with the precepts of the Declaration of Helsinki and the Nuremberg Code, respecting the Standards for Research involving human beings of the National Health Council. An informed written consent was obtained from all participants of the study.

Consent for Publication: This manuscript is being submitted only to BMC Medical Education and it will not be submitted elsewhere while under consideration. All authors read, reviewed, and approved the final version of the manuscript.

Availability of data and materials: The complete database is available on request with the corresponding author.

Competing interests: nothing to declare.

Funding: nothing to declare.

Authors' contributions: MDMG, RG and JFMO have participated in the concept and design, analysis and interpretation of data, drafting and revising the manuscript. AS has participated in design, statistical analysis and interpretation of data, drafting and revising the manuscript. ACYP, MFC, MDK, MHM and MFBA have participated in the design of the study, interpretation of data, and revising the manuscript. All authors listed on the manuscript approved the submission of this version of the manuscript and take full responsibility for the manuscript. The authors declare that they do not have any conflict of interest. None of authors received any form of payment to produce the manuscript.

Acknowledgements: Neonatal Simulation Research Group of Federal University of São Paulo.

\section{References}

1. You D, Hug L, Ejdemyr S, Idele P, Hogan D, Mathers C, et al.: Global, regional, and national levels and trends in under-5 mortality between 1990 and 2015, with scenario-based projections to 2030: a systematic analysis by the UN Inter-agency Group for Child Mortality Estimation. Lancet. 2015, 386:2275-86.

2. World Health Organization (WHO). Newborns: improving survival and well-being. Web site. https://www.who.int/news-room/fact-sheets/detail/newborns-reducing-mortality. Accessed 2020 Nov 17.

3. Wang H, Liddell CA, Coates MM, Mooney MD, Levitz CE, Schumacher AE, et al.: Global, regional, and national levels of neonatal, infant, and under-5 mortality during 1990-2013: a systematic analysis for the global Burden of Disease Study 2013. Lancet. 2014, 384:957-79.

4. Lee AC, Cousens S, Wall SN, Niermeyer S, Darmstadt GL, Carlo WA, et al.: Neonatal resuscitation and immediate newborn assessment and stimulation for the prevention of neonatal deaths: a systematic review, meta-analysis and Delphi estimation of mortality effect. BMC Public Health. 2011, 11:S12. 
5. Halamek LP, Association of Medical School Pediatric Department Chairs Inc: Teaching versus learning and the role of simulation-based training in pediatrics. J Pediatr. 2007, 151:329-30.

6. The Joint Commission. Sentinel event 30: Preventing infant death and injury during delivery. Web site. https://www.jointcommission.org/-/media/tjc/documents/resources/patient-safetytopics/sentinel-event/sea_30.pdf. 2004. Accessed October 20, 2020.

7. The Joint Commission. Sentinel event data. Root causes by event type 2004-2014. https://www.jointcommission.org/-/media//tjc/documents/resources/patient-safety-topics/sentinelevent/root_causes_by_event_type_2004-2014.pdf? $\mathrm{db}=$ web\&hash=6E76D1931B9208849FF7F6BE8543FB1E. Accessed June 15, 2021.

8. Sawyer T, Lee HC, Aziz K. Anticipation and preparation for every delivery room resuscitation. Semin Fetal Neonatal Med. 2018,23(5):312-20.

9. Wyckoff MH, Wyllie J, Aziz K, de Almeida MF, Fabres J, Fawke J, et al. Neonatal Life Support: 2020 International Consensus on Cardiopulmonary Resuscitation and Emergency Cardiovascular Care Science With Treatment Recommendations. Circulation. 2020,142(16_suppl_1):S185-S221.

10. O'Currain E, Davis PG, Thio M: Educational perspectives: toward more effective neonatal resuscitation: assessing and improving clinical skills. Neoreviews. 2019, 20:248-57.

11. Knowles MS, Holton EF, Swanson RA: The adult learner: the definitive classic in adult education and human resource development, 7th edition. Amsterdam, Boston: Elsevier, 2011, pp 406.

12. Sauer Jr CJ. Realistic simulation methodology in Brazil's new medical education curriculum: Intern Scholar Scient Res Innovat 2020: 14: 833-35.

13. Halamek LP: The simulated delivery-room environment as the future modality for acquiring and maintaining skills in fetal and neonatal resuscitation. Semin Fetal Neonatal Med. 2008, 13:448-53.

14. LeFlore JL, Anderson M, Michael JL, Engle WD, Anderson J: Comparison of self-directed learning versus instructor-modeled learning during a simulated clinical experience. Simul Healthc. 2007, 2:170-7.

15. LeFlore JL, Anderson M. Alternative educational models for interdisciplinary student teams. Simul Healthc. 2009,4:135-42.

16. Anderson JM, Murphy AA, Boyle KB, Yaeger KA, Halamek LP. Simulating extracorporeal membrane oxygenation emergencies to improve human performance. Part II: assessment of technical and behavioral skills. Simul Healthc. 2006,1:228-32.

17. Sawyer T, Leonard D, Sierocka-Castaneda A, Chan D, Thompson M: Correlations between technical skills and behavioral skills in simulated neonatal resuscitations. J Perinatol. 2014,34.:781-6.

18. Anderson M, LeFlore JL, Anderson J M. . Evaluating videotaped role-modeling to teach crisis resource management principles. Clin Simul Nurs. 2013,9:343-54.

19. Beck AT, Steer RA: Beck Anxiety Inventory Manual, $1^{\text {st }}$ edition. Texas, Psychological Corporation, 1993. 
20. Cunha JA: Manual da versão em português das escalas Beck, $1^{\text {st }}$ edition. São Paulo, Casa do Psicologo, 2001.

21. Lee HC, Chitkara R, Halamek LP, Hintz SR: A national survey of pediatric residents and delivery room training experience. J Pediatr. 2010, 157:158-61.

22. Cronbach LJ: Coefficient alpha and the internal structure of tests. Psychometrika 1951, 297-334.

23. Altman DG: Practical statistics for medical research, $1^{\text {st }}$ edition. London, Chapman and Hall, 1991.

24. Hartling L, Hamm M, Milne A, Vandermeer B, Santaguida PL, Ansari M, et al:. Validity and inter-rater reliability testing of quality assessment instruments [Internet]. Rockville (MD): Agency for Healthcare Research and Quality (US), 2012. Report No.: 12-EHC039-EF.

25. Taylor DC, Hamdy H: Adult learning theories: implications for learning and teaching in medical education: AMEE Guide No. 83. Med Teach.. 2013, 35:1561-72.

26. Patel J, Posencheg M, Ades A: Proficiency and retention of neonatal resuscitation skills by pediatric residents. Pediatrics. 2012, 130:515-21.

27. Matterson HH, Szyld D, Green BR, Howell HB, Pusic MV, Mally PV, et al.: Neonatal resuscitation experience curves: simulation-based mastery learning booster sessions and skill decay patterns among pediatric residents. J Perinat Med. 2018, 46:934-41.

28. Al-Ghareeb A, McKenna L, Cooper S: The influence of anxiety on student nurse performance in a simulated clinical setting: A mixed methods design. Int J Nurs Stud. 2019, 98:57-66.

29. Yuan HB, Williams, BA, Fang, JB: The contribution of high-fidelity simulation to nursing students' confidence and competence: a systematic review. Int Nurs Rev. 2012, 59:26-33.

30. Labrague LJ, McEnroe-Petitte DM, Bowling AM, Nwafor CE, Tsaras K: High-fidelity simulation and nursing students' anxiety and self-confidence: a systematic review. Nurs Forum. 2019, 54:358-68.

\section{Figures}




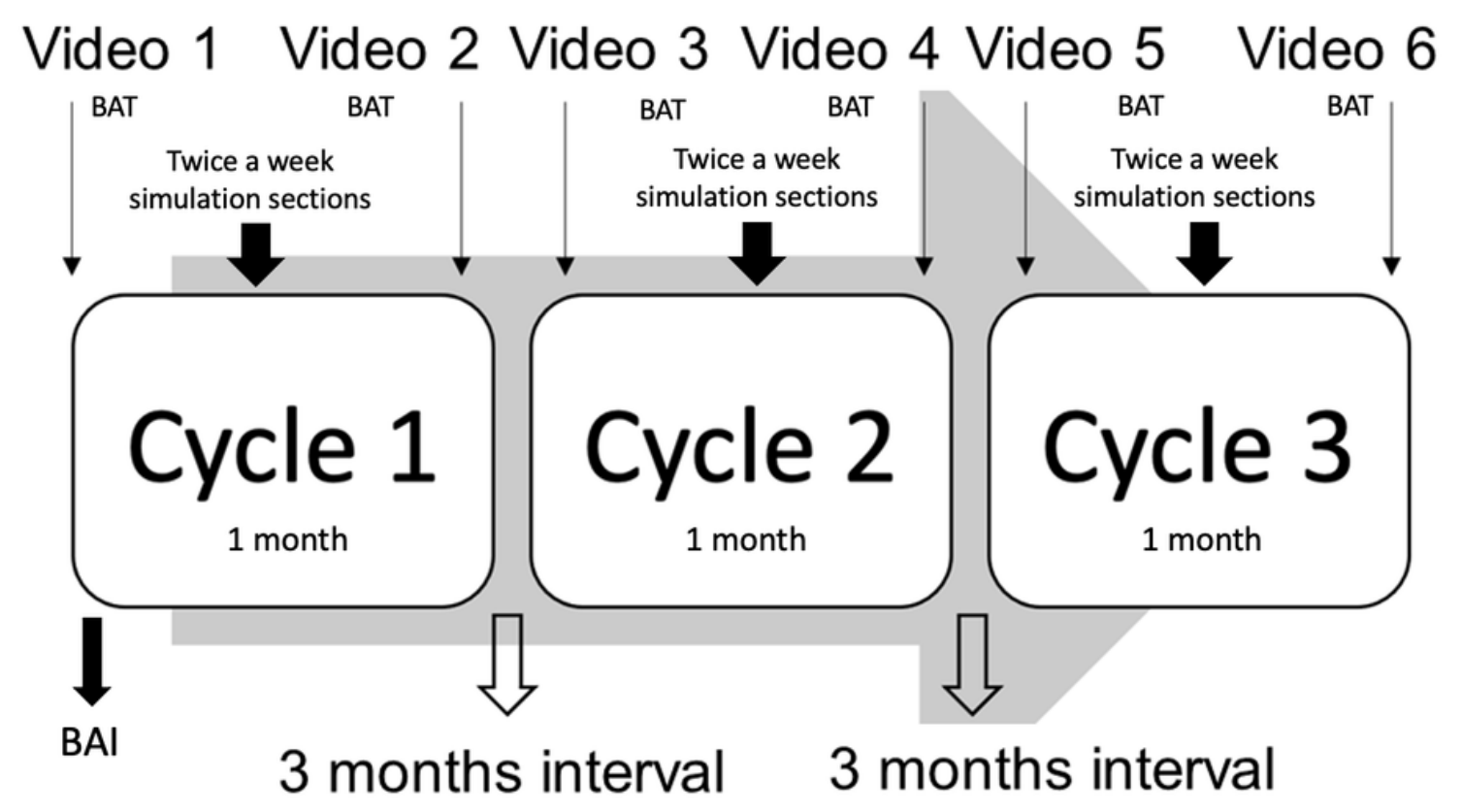

BAl: Beck Anxiety Inventory

BAT: Behavioral Assessment Tool

Figure 1

Distribution of videos and training cycles

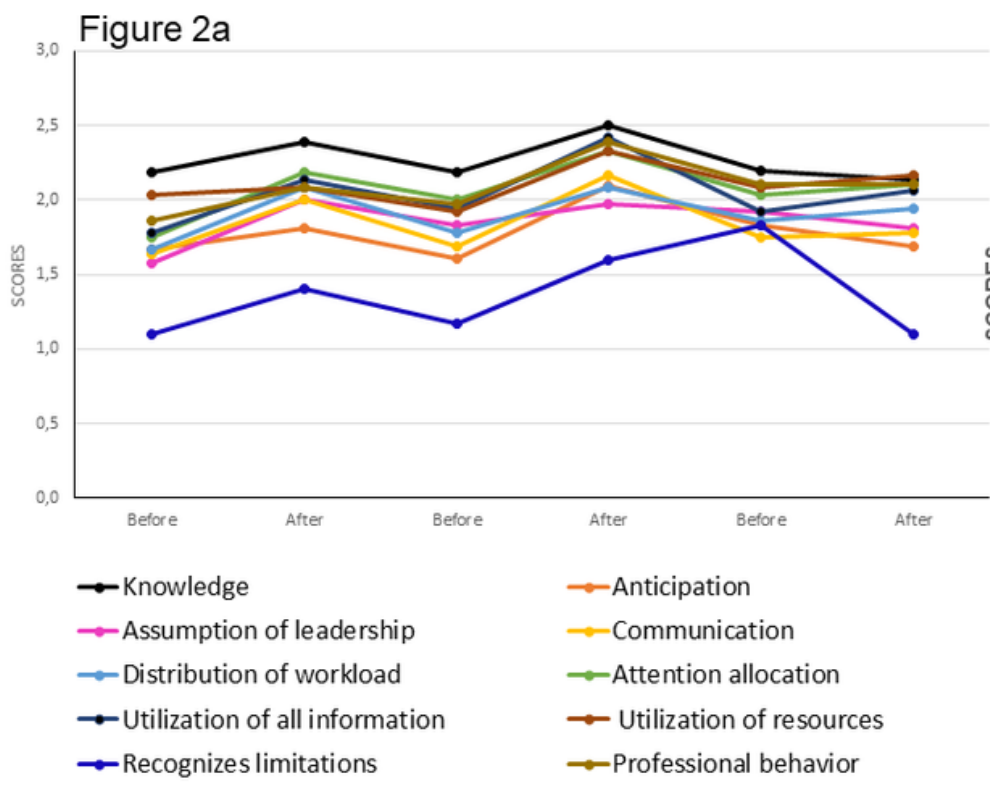

Figure 2b

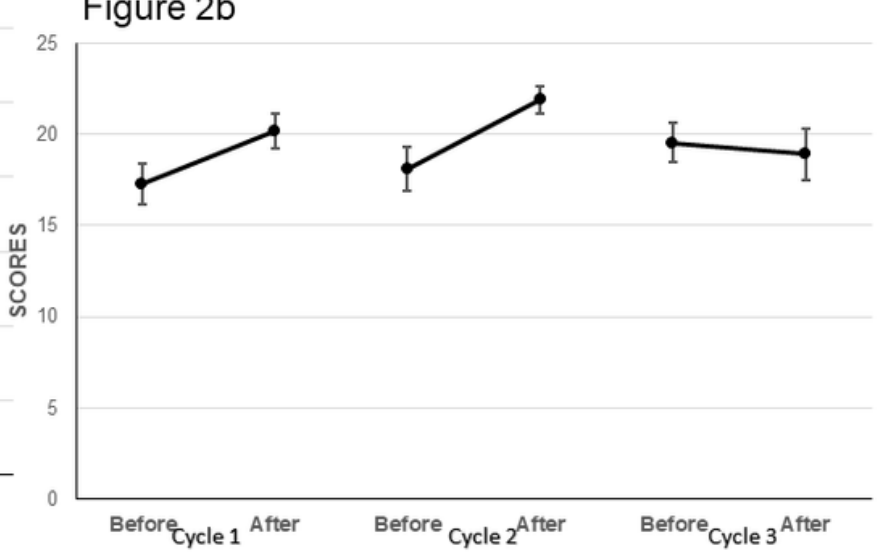

Figure 2 
Acquisition of behavioral skills during the training cycles according to the BAT scale. 2a: Mean scores of each Learning curve of each behavioral domains. $2 b$ : Mean \pm standard error of the total score. 